This item was submitted to Loughborough's Research Repository by the author.

Items in Figshare are protected by copyright, with all rights reserved, unless otherwise indicated.

\title{
Book Review: Misinformation and Mass Audiences
}

PLEASE CITE THE PUBLISHED VERSION

https://doi.org/10.1177/1940161218820859

PUBLISHER

(C) The Authors. Published by SAGE Publications

\section{VERSION}

AM (Accepted Manuscript)

\section{PUBLISHER STATEMENT}

This work is made available according to the conditions of the Creative Commons Attribution-NonCommercialNoDerivatives 4.0 International (CC BY-NC-ND 4.0) licence. Full details of this licence are available at: https://creativecommons.org/licenses/by-nc-nd/4.0/

\section{LICENCE}

CC BY-NC-ND 4.0

\section{REPOSITORY RECORD}

Chadwick, Andrew. 2019. "Book Review: Misinformation and Mass Audiences". figshare. https://hdl.handle.net/2134/36296. 
Review for International Journal of Press/Politics

November 28, 2018

Brian G. Southwell, Emily A. Thorson, and Laura Sheble (eds.) Misinformation and Mass Audiences. Austin, TX: University of Texas Press, 2018.

Reviewed by: Andrew Chadwick, Loughborough University, Loughborough, Leicestershire, UK.

Author's accepted manuscript (pre-typeset).

"Crisis" is an over-used word in the social sciences, but it captures the current moment in political communication. The great digital disruption of the last twenty years has had consequences few could have predicted. At the tail end of the broadcast era there was an overwhelming sense of ennui about the ways television had reshaped political life. Commentary about the "dumbing down" of public discourse, elite-driven manipulation of news, and the disengagement of ordinary citizens from politics became the norm. It was the culmination of a 30 -year process of political adaptation to broadcast media logics. The current crisis of public communication has spurred a similarly pessimistic turn in scholarship on media and politics. Where once the organizing paradigm was "engagement," the emergent wave of recent research on fake news and computational propaganda rightly takes us "back to the future" of political 
communication research, with a retro-revivalist focus on classic questions of public rationality and the nature of the public sphere.

There is mounting descriptive evidence that social media platforms are producing systemic and democratically-dysfunctional effects, many of which stem from the incentive structures the platforms' business models have established among both elites and mass publics. The current concerns over bots, hacks, surveillance, algorithmic distortion, and outright fakery are obvious examples. However, the scholarly agenda for researching the long-term consequences of these phenomena for individual attitudes and behavior is only just taking shape. Familiar nostrums such as "minimal effects" and the "active audience," which were refined during the dying days of the broadcast era as part of a critique of media effects research, do not quite seem to have the required traction in our new context of intimate, small-screen, interfaces, micro-targeting, and the datafication of so many aspects of human existence. And yet, it is also clear that the theories and research designs typical of broadcast era media effects research do not quite seem to work either. This new edited volume on Misinformation and Mass Audiences is by no means perfect, but it makes a good start down the road of identifying the kinds of concepts and methods needed if we are to comprehend the difference social media make when they interact with the factors that shape individuals' knowledge and attitudes toward politics and policy. The emergent post-2016 organizing paradigm is not engagement but influence-warts-and-all.

Brian G. Southwell, Emily A. Thorson, and Laura Sheble have assembled an interesting and cogent set of contributions to this new intellectual task, making this an 
excellent introduction to the complex roots of misinformation. The book adopts a useful multidisciplinary approach that draws upon scholarship in communication, psychology, political science, information science, marketing, and public health research. It also contains a whole section examining how research findings have been used to try to combat the spread of misinformation. Uniting the authors is a focus on the individuallevel factors that shape the spread of misinformation and misperceptions. In the editors' Conclusion they make a useful distinction between these two things, arguing that misinformation is false information while misperceptions are false beliefs. The key point is that one does not automatically lead to the other. There are plenty of scenarios in which individuals will reject misinformation, just as there are plenty of scenarios in which misperceptions will arise in the context of perfectly good information. Indeed, exploring this interface-between the variable quality of information available in the public domain and the human frailties that shape how individuals are able to make sense of it-is one key to progress in the field.

Each of the chapters adopts the same basic orienting framework-information quality meets (mostly) psychological variables -though the objects of analysis vary. The chapters cover, for example, false beliefs about health risks and climate science, misleading content in advertisements, the characteristic media usage behavior that tends to lead to susceptibility to misinformation, the growth of fact-checking in U.S. politics, and the debate over whether political satire constitutes misinformation.

The latter, a particularly thoughtful chapter by Dannagal G. Young that focuses on the complexities of ironic humor, says much about the crossroads we have reached 
as a field. Over the last fifteen years there has been an outpouring of research on the broadly positive civic effects of political satire-think The Daily Show. But, aside from a few exceptions, there has been surprisingly little attention to the psychological mechanisms that actually make it work-or fail to work, as proves to be the case more often than we realized. Young argues that satire can be distinguished from misinformation because it contains visible contextual markers that cue audiences to invert the surface meaning of a text. Satirists will go to great pains to signal these cues as part of the construction of irony. And yet two forces get in the way of this seemingly simple formula. First, due to knowledge gaps, many audience members either undervalue or simply do not "get" political satire. Second, and more worryingly, the construction and distribution of political satire is itself changing as digital media proliferate. Many of the contextual source cues that make traditional satire work are either missing or only loosely anchored in the "news feed" affordance that is now at the core of most people's online experience. This is one aspect of the much broader problem of indeterminacy in online spaces, including news. Over time, the most likely outcome from these and related developments is not so much the transmission of false beliefs as a general sense of confusion and distrust.

This brings me to what are really the only two weaknesses in this refreshingly coherent and timely contribution to the literature. First, while some of the chapters hint at how media affordances might make a difference to the spread of misinformation, too often these remain just hints. I was left wondering how the differences between specific media come to matter when they are added to the mix of social and psychological 
variables cognitive scientists have classically used to explain why misinformation takes hold. Perhaps this is a narrower way of saying that the present crisis requires some integration of concepts and methods of cognitive science with those of communication and journalism studies. Cognitive scientists have developed a sophisticated experimental literature explaining the variation in individuals' susceptibility to fakery; communication and journalism scholars (and those working in science and technology studies) have produced convincing accounts of why different media can enable and constrain individual behaviors. Let's bring them together.

Few of the chapters in this book attempt this kind of integrative work, though some get closer than others. Brian Weeks' clear and concise overview of the roots of political misperceptions integrates some useful reflections on what happens when social media interact with group identity, diversity of social networks, selective exposure, and motivated reasoning. Jeff Hemsley's chapter usefully integrates Karin Nahon's "networked gatekeeping" framework with Kjerstin Thorson and Chris Wells' suggestive concept of "curated flows." But overall the volume tends to sidestep the crucial issue of precisely how and why different media, and more pertinently, social media platforms, might make a difference to the distribution and impact of misinformation.

The book's second weakness is that many chapters lack a coherent account of how misinformation comes to be structured by the strategic behavior of political and media elites who routinely introduce problematic information of various kinds-rumors, half-truths, exaggeration, and decontextualized statements-as part of their daily practice, further adding to the growing culture of indeterminacy online. This becomes all 
the more problematic in a context in which, despite the growth of user-generated content and secondary gatekeeping, elite cues still appear to be highly important, not least because they act of the essential resources that non-elites respond to and then choose to share on social media, in order to exert influence over others in their social media networks.

Overall, this book is a clear and concise introduction to many of the important themes in misinformation studies. It is a valuable contribution to the new research agenda taking shape in political communication research. 